\title{
DOCUMENTING THE CONSERVATIVE EVOLUTION OF THE CITY WALLS THANKS TO THE INTEGRATION OF DIGITAL SYSTEMS OF VARIOUS TYPOLOGIES. THE CASE STUDY OF VALBONA GATE
}

\author{
L.Baratin $^{1}{ }^{*}$, A.Cattaneo $^{1}$, F.Gasparetto ${ }^{2}$, E.Moretti ${ }^{1}$, S. Lonati $^{3}$ \\ ${ }^{1}$ Conservation and Restoration school, DiSPeA, Piazza della Repubblica, 13, University of Urbino PU, (laura.baratin, \\ alessandra.cattaneo, elvio.moretti)@uniurb.it \\ ${ }^{2}$ DICEA, via Brecce Bianche, University Politecnica delle Marche, Ancona AN, fnc.gasparetto@gmail.com \\ ${ }^{3}$ SERVONET snc, Via Tito Speri, 38-40, 25082 Botticino BS, stefano@ servonet.it
}

Commission VI, WG VI/4

KEY WORDS: 3D, GIS, conservation, digital documentation, cultural heritage

\begin{abstract}
:
The presented study describes how to document in a dynamic way a complex and full of historical information architecture with a flexible system. Thanks to the collaboration between various professional figures and the integration of various digital systems, it has been possible to create an open documentary model able to satisfy the need to manage complex information.

Our case study is the Valbona gate, the main entrance of the city of Urbino. The project presents two different phases: a first study is characterised by the setting up of a Datawarehouse concerning state of conservation and restoration managed with a GIS system; the second part is focused on a new type of documentation, developed with an online software, CDR - Conservation Digital Report.

Thanks to the capacity of organising all data into a single Geodatabase system, the information relating to the conservation status and to deterioration, restoration interventions carried out.

The result is a geodatabase linked with conservative sheets expressly scheduled. In this way the documentation is completed by a system which allows a simple updating of information and its implementation, if necessary.
\end{abstract}

\section{INTRODUCTION}

The work shown in the contribution is part of a broader research project, which involves the entire city walls of Urbino. In addition to the survey of the architectural structure, examination focuses are being developed respect specific portions. The requirement to structure an integrated system - that allows a rapid consultation of data - comes from the amount of information of various kinds collected during the work.

Considering the importance of the historical centre of Urbino, an UNESCO World Heritage Site since 1998, many works have already been developed in this regard (Baratin et al. 2015a; Baratin et al. 2015b; Baratin et al. 2016a) with important results for the type of research we are conducting today.

We have chosen to deepen the case study of the Porta Valbona, already recently the subject of experiments (Bertozzi et al., 2016). Starting from the results obtained, we decided to implement the technical result given the new information collected about the door. In fact, the research group has expanded, including new professional figures, in order to obtain an integrated and functioning documentation system within the reach of all professionals.

\subsection{Research aim}

Our idea started from the need to bring together different levels of data collected about an architectural object that is still fully functional as access to the city. The information collected within the same system concerns historical, technical, conservative and design data. Each of these sets was collected by different professionals, at different times and necessarily related to each other. We therefore needed a system that would not only relate the data, but would also organize it according to a timeline, thus creating a historical one.

The eclectic nature of the information to be stored meant that our system had to be flexible and continuously integrable, without losing a certain order every time it was expanded.

\subsection{Related work}

The topic of managing a lot of information related to a building has been the focus of documentation research for many years. The new approach to the modern management of Cultural Heritage aims to collect and organize as efficiently as possible all the information and data about the site, in order to facilitate the planning for future interventions or for the preparation of a maintenance plan of the asset under intervention.

One of the main problems, underlined by the various studies carried out, is the ability to manage different information concerning the same architectural object. In fact, many researches have emphasised the importance of having the possibility to manage multilayer documentation, not only at urbanistic level but also on a smaller scale (Florenzano et al. 2011; Pecchioli et al., 2011). Other experiments have carried out applications of web-based systems, such as SiCaR. These are an example of how the objective is represented by the need to work by organizing information of various kinds with a tool that supports both during the preliminary studies phase of the restoration project and during the construction site itself. In fact, the need to collect data, to make them questionable and useful for design purposes for restoration interventions are the starting point of experiments in the field of documentation.

\footnotetext{
* Corresponding author
} 
From the query mapping developed by the $\mathrm{SiCaR}$ system to the BIM systems used for enhancement and conservation purposes, the final goal is to obtain a tool that is able to network all the data (Lo Turco, et al., 2017). For BIM environments, the focus of this work is the identification of standards - technical, material and degradation parametric references - that help in a simplified mapping and easier to manage. In other cases, the data stored in an experimental HBIM has been merged into GIS systems in order to obtain results on a territorial scale. The advantages of combining two systems created for different purposes are immediately clear (Dore and Murphy 2012).

Attempts to develop integrated documentation systems have therefore been at the heart of the research field that combines documentation and digital representation for many years. This necessarily entails a problem related to the organization of multiple types of representations and dialogue between the collected data.

To date, it has certainly been demonstrated the need and importance of 3D surveys in order to better manage the data collected and as a starting point around which to develop methods of data storage and reading (Yaagoubi et al. 2019).

\section{GENERAL APPROACH}

2.1 The case-study: the Valbona gate and its restoration interventions

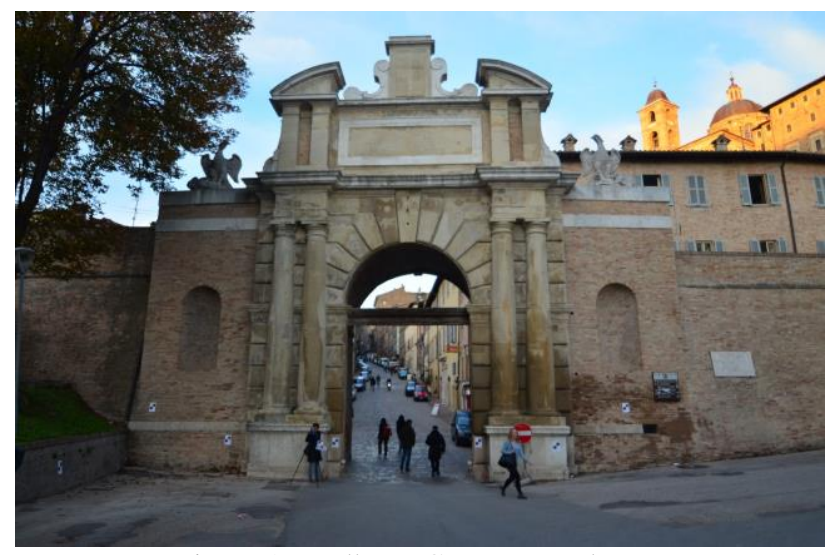

Figure 1 - Valbona Gate, external part.

Porta Valbona represents, together with the city walls, an exceptional case of sedimentation and stratification that, despite the events, still today allows to reconstruct its historical events. In the vast Piazzale del Mercatale (Market Square), which owes its name to the fairs and markets that were held there in the past, rises Valbona Gate, the architectural construction connected to the city walls, designed and built by the Urbino architect, Sigismondo Albani. Built in 1621, it is the most important gate in the city, both because it is connected to Via Mazzini - one of the main streets of the old town - and because of its scenic architectural design planned for the wedding between Prince Frederico Ubaldo della Rovere and Princess Claudia de 'Medici. This Gate is the exception, built with stone and bricks even though it was known that the wedding procession and the bride and groom would stay in Urbino just one night.

The two limestone eagles, placed at the sides of the door, date back to the middle of the eighteenth century; they are the work of the architect Giovan Francesco Buonamici from Rimini.

It is also the only gate in the city that has a monumental decoration to the external part (facing Mercatale's square).

In general, it is an architectural product that is perfectly up-todate with the examples of the late Mannerist and Baroque period, very probably derived from the models of the Treatise by Sebastiano Serlio, with the face having smooth ashlars to act as a background to the pairs of lateral semi-columns supporting an inscription.

Still today the gate is the main access to the city. Valbona Gate is the most important of the seven gates that are part of the city walls of Urbino.

Although it has undergone several restorations and consolidations over the centuries, it has not been modified in its original appearance.

Valbona Gate has always created many problems linked to deterioration, especially of the stone material, for which various interventions of restoration were carried out, indispensable for reaching the current state of conservation. The first was carried out by Mastro Silvio Tommasini in 1755 and it focused mostly on the ornamental part and on the stabilisation of the two eagles, work by the architect Giovan Francesco Buonamici.

Included in the context of the same restoration, reinforcements were made to the wall alongside the Gate. In 1825 it was Giuseppe Corsini who undertook some repairs and restoration on the external monumental part.

It was then the turn of the Technical Officer of the Municipality of Urbino who, on 27 September 1873 approved a project for the removal of a public fountain which was close to the door. A subsequent appraisal dated 17 October 1873 highlighted the severe conditions of deterioration involving the entire gate and he ensured that work of a structural type of restoration would be carried out with extreme urgency. Despite the work carried out, in 1784 there was the need once again for a major intervention of consolidation and maintenance.

Also, in the $1950 \mathrm{~s}$, it was necessary to intervene with other structural work, a result of which was the walkway above the gate being created, by removing some houses the two ends of via Mazzini were connected, as well as other minor changes including the insertion of an epigraph at the summit of the pediment that testified the restoration work carried out in those years.

The last restoration interventions in order of time date back to 1985-1986 and were carried out by the firm Carli and again in 1995 by the same company on indications of Croci.

\subsection{The documental approach to case-study}

The applied planning method was based on the following analyses:

a) urban analysis: knowledge of the characteristics and urban potential of the gate;

b) historical analysis: knowledge of the historical evolution and of the specific qualities of the gate;

c) geometric analysis: metric and architectural surveys;

d) material analysis: study of materials and deterioration pathologies;

e) structural analysis: identification of the morphological and constructive organization from the structural point of view.

All the large amount of information obtained from the analyses was managed thanks to the use of GIS systems combined with CDReport software. The shape and character of the monument were identified and the testimonial, constructive and architectural values were recognized.

Each step has produced a series of specific information differently managed. All that concerned the structure and geometry of the architecture was included in GIS, while what more closely related to the descriptive aspect of the state of conservation and the materials used was described with CDReport. 
As you can guess, the two systems have two different goals. CDReport stores descriptive information, captions, diagnostic data and jpeg images. It is a more precise tool, which allows to deepen detailed information about a specific part of the object. GIS, on the other hand, works like a real geodatabase, locating information on facade and plant. Furthermore, the data entered in GIS can be queried, analyzed in their complexity. This indispensable process, carried out through forms of analytical and scientific knowledge, led the research group to the recognition of values and therefore to a conscious plan and to an enhancement project. Based on an internal analysis of the cultural asset and an external analysis of the context in which our case-study is located, the latter was able to define the strengths, weaknesses, opportunities and threats.

\subsection{Structuring a new geodatabase for implementation}

The initial process is therefore based on a series of surveying operations, aimed at controlling the dimensional consistency, the characterisation of the various descriptive typologies (history, techniques, materials, form and nature of deterioration, etc.) and to the creation of the basis on which to operate the subsequent analysis and study of the themes, to then move to a stage of display and fruition of the data, within which it is possible to manage a reconstruction of reality in a highly flexible way, that is, one that is useful for diverse types of end users.

Direct and photographic surveys have led to aerial photography renderings that shall integrate the topographical survey through total station, carried out through topographical points identified by architectural targets and the point clouds deriving from the laser scanner. The entire step of alignment and cleaning of the clouds has led to the creation of the grid and the 3D model, allowing the insertion of horizontal and vertical planes that define plans, prospectuses and sections of the final architectural and metric surveying. The graphic rendering, all the iconographic documentation and information on the material characteristics and on the various surveys executed in the course of time on the gate and on the evolution of its conformation, were integrated into a GIS system (ArcGIS in its latest version) which allows the analysis and management in two- and threedimensional environments. The 3D surveys were also modelled to define the various phases of evolution of the architectural shape of the gate, starting from the second half of the fifteenth century to its current definition.

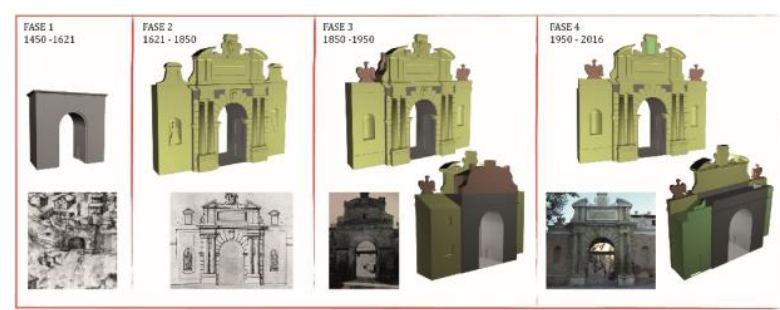

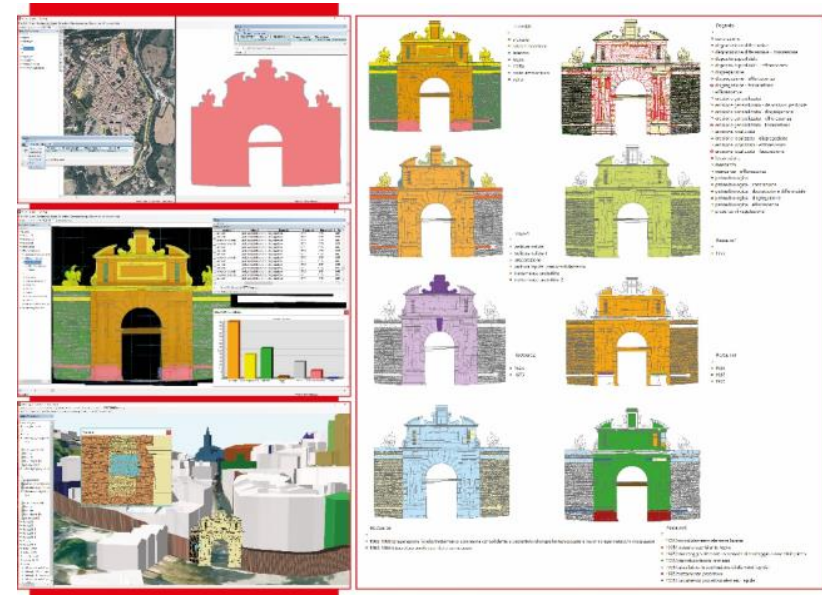

Figure 2. 3D reconstruction of the various building phases that have affected Porta Valbona

\subsection{CDReport: a new system to integrate various information}

It is very interesting to use a web tool because there are many different professional figures who collaborate in the editing of the Porta Valbona documentation. In fact, the possibility of working on line allows the immediate and continuous sharing of data. The idea behind CDReport is open access. Like other online platforms, it is possible to access them according to three different profiles depending on the professional role and the information that must be entered. The administrator has a wide margin of movement, organizational freedom of the form and possibility of control of any information entered, the collaborator instead can only fill in the fields assigned to him, the guest can only read without interacting. This difference in roles allows you to manage the data and the people responsible for the entry. The possibility to access only to view the data makes the platform useful also for communication purposes, not only technical. This is an innovative aspect for systems that manage data relating to restoration sites, normally available only to professionals. The new perspective opens up with an emphasis on the importance of data accessibility.

The innovative aspect of the project is not only the use of the CDReport platform for architecture, adapted for the first time to an architectural site, but its direct connection with a GIS system. Even though the work started from a structuring on GIS of the most general information collected, the research wanted to experiment a new pipline that sees the CDR sheet as the focus of the entire documentation, which only in a second phase connects to the relational structure of the GIS project.

The CDReport system responds very well to the need to store a lot of information. Thanks to its synthetic and flexible structure, it allows to insert any kind of descriptive data. In addition, there is the possibility to attach images, general and detailed, and 3D models.

The experimentation that connects the CDR digital records to a database organized by a GIS system makes the documentation expandable, according to the levels of interest.

\subsubsection{The genesis of CDReport application}

CDReport (Conservation Digital Report, www.cdreport.eu) was created as a flexible and interactive database at the service of museum artfacts and their transport between exhibitions and collections. Its great potential is to be able to manage many data of various kinds thanks to the possibility of structuring the database according to the needs of the operator and the kind of 
work. Moreover, its open-source logic allows it to be continuously implemented and updated, while maintaining a fixed skeleton from which to start.

It is possible to have the option of attaching files and managing 3D models inside digital documents you create.

Already tested as a documentation system for small artefacts (Baratin et al., 2016b) and in emergency contexts also to document works related to architecture, such as frescoes (Baratin et al., 2017a), the CDReport software has been modeled on this occasion for various purposes.

\subsubsection{The practical methodology}

In the field of documentation for cultural heritage there is no real standard of being closely related. For this reason, it is necessary to address the issue from within, identifying the needs of the case study. In this sense CDReport allows to respond to the needs of documentation in a very efficient way. Starting from the analysis of the needs that a database that manages information about architectures must have, we have identified three objectives, from which our experimentation started:

1. To identify a relational method that allows to link data of various nature concerning a complex object;

2. To develop an interactive and expandable system, which takes into account the different levels of detail of the various professional figures who work on an architectural site;

3. Organize the data entered according to a temporal order, which makes it possible to understand the succession of the work phases.

The first step was to design the filing, the organization of its macro-themes. Starting from the experiments carried out in the field of wooden sculptures, painted on different supports and artifacts of various kinds (Baratin et al., 2016c; Baratin et al., 2017b), we have developed an alternative filing system more suitable for the type of object under examination.

Il CDReport è strutturato al suo interno secondo uno schema che prevede la suddivisione dei gruppi informativi in due categorie: una dedicata alle informazioni generali e un'altra specifica per i gruppi strettamente collegati alla tipologia architettonica dell'edificio che si sta studiando.

L'operatore può definire i campi in base alle proprie necessità. In questo caso, abbiamo creato una nuova tipologia, chiamata "Porta - Cinta muraria", per la quale si è progettata una schedatura digitale specifica, con gruppi e campi da compilare adatti al nostro caso studio.

Nella sezione "Gruppi tipologia" sono stati quindi inseriti i gruppi specifici, come i materiali impiegati o l'analisi del degrado che interessa le varie parti dell'edificio.

The CDReport system is structured internally according to a scheme which divides the information groups into two categories: one dedicated to general information and another specific for groups closely linked to the type of architecture of the building being studied.

The operator can define the fields according to his needs. In this case, we have created a new typology, called "Door - Walls Belt", for which a specific digital filing system has been designed, with groups and fields to be filled in suitable for our case study.

In the section "Typology groups" we have therefore included the specific groups, such as the materials used or the analysis of the degradation that affects the various parts of the building.

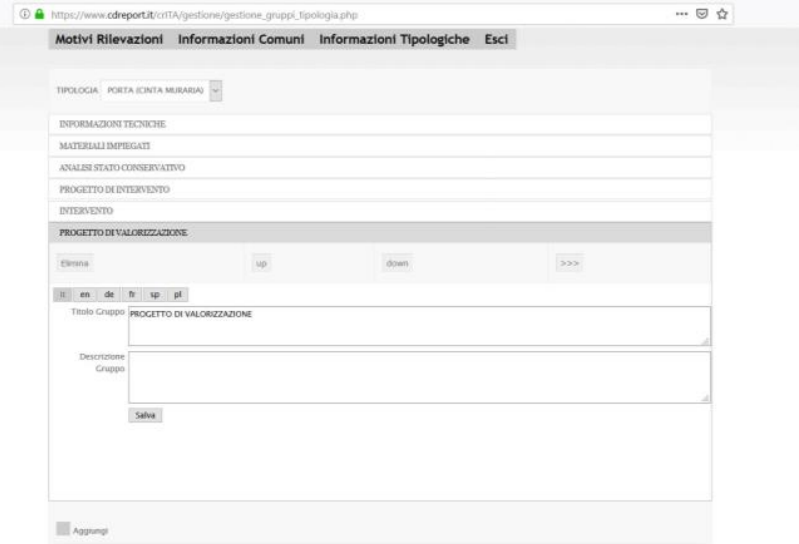

Figure 3. CDR interface: structural part

As you can see in the image, the software allows to structure the scheduling according to your needs, giving the fields specific definitions.

Once the project part has been completed, we have moved on to the compilation of the filing. Then, once the space dedicated to our case study had been created within the software, we went on to compile it.

Each digital filing is organized into surveys. Inside the space dedicated to our building you can have several surveys, listed sequentially according to when they were carried out. This automatically creates a history of the operations carried out on the architectural object.

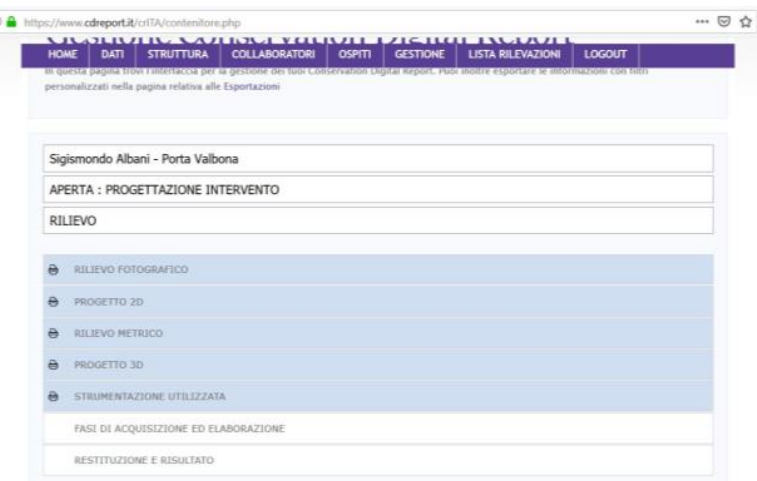

Figure 4. CDR interface: fields to be filled

Each group of information is filled in with descriptive fields, which are gradually completed with texts. JPEG images or PDF documents can be associated with each field. Detailed images can be located on a graphical reference frame. This allows to obtain a descriptive report, implemented by previously made maps, descriptive images and scientific reports (such as results of diagnostic investigations).

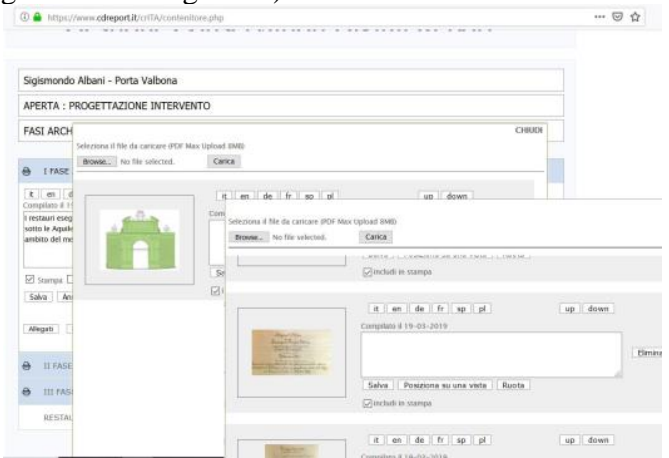

Figure 5. CDR interface: possibility to attach JPG and PDF files 
The result of the compilation can have two different outputs. The documentation created can be printed out in PDF format; a second possibility is the creation of the digital form. The information collected is organized in an HTML page, whose internet address will be inserted into the table of attributes of the GIS project.

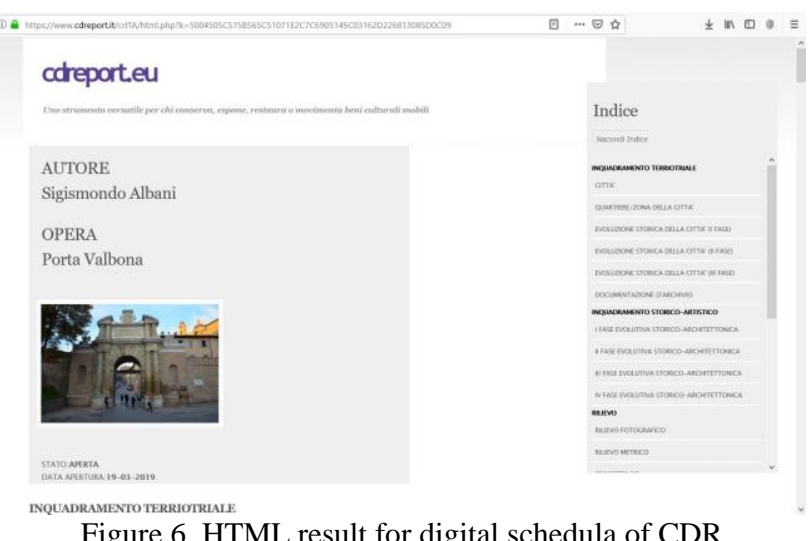

In this way, by attaching the link of an architectural object within the table in GIS, you have access to more details of the parts of the detected object. The GIS allows you to move on the architectural surface of the facade of the door, identifying the areas of interest, questioning them with the tools of the geodatabase and being able to deepen historical, conservative and design information through the possible connection through the hyperlink.

\section{THE FINAL GOAL: AN INTEGRATED DOCUMENTATION}

The data collected concerning our case study, Porta Valbona, needed to be organized in depth according to three levels of information: representative, managerial and structural. We tried to use the two systems at our disposal to find a practical solution. We thus realized how the software could be integrated with each other, thus designing a working methodology even in the data collection phase:

\section{REPRENTATIVE LEVEL: managed and} solved by the GIS project, which collects dimensional and geometric information thanks to its ability to manage two-dimensional and three-dimensional processes;

2. MANAGEMENT LEVEL: developed by the CDR for architecture, which by its nature is a flexible system, open to various accesses according to different needs, totally buildable at any time;

3. STRUCTURAL LEVEL: developed by the CDR for architecture that presents an organization of the cards within its system according to the sequentiality with which the cards are inserted, thus creating a clearly legible history of the operations carried out on the artifact.

The intrinsic characteristics of the two softwares, as well as the final products of the two systems are clearly different. The interaction between the two software undoubtedly allows an exhaustive integration for the documentation, which becomes in this way complete and thorough. The use of GIS allows to cross data and to obtain quantitative information, while the use of CDReport allows to have available the historical information of the archive, the qualitative data of the materials, the state of conservation and the project of intervention.

\section{REFERENCES}

Florenzano, M. et al. 2011. "Computers \& Graphics A Semantic-Based Platform for the Digital Analysis of Architectural Heritage.” 35: 227-41.

Dore, C, and M Murphy. 2012. "Integration of Historic Building Information Modeling ( HBIM ) and 3D GIS for Recording and Managing Cultural Heritage Sites." 2012 18th International Conference on Virtual Systems and Multimedia: 369-76.

Baratin, L., Bertozzi, S., Moretti, E. 2015a. The Geomorphological transformations of the City of Urbino: the design of the city analysed with GIS tools. SCIRES it, SCIentific RESearch and Information Technology, vol. 5, no. 1, pp. 4160. e- ISSN 2239- 4303, doi 10.2423/i22394303v5n1pp41 (C) CASPUR-CIBER Publishing, http://caspur-ciberpublishing.it.

Baratin, L., Bertozzi, S., Moretti, E. 2015b. GIS intelligence for a cutting-edge management of 3D Cities. Digital Heritage International Congress 2015, Granada, Spain.

Baratin, L., Bertozzi, S., Moretti, E. 2016a. Le trasformazioni della città di Urbino durante il periodo dei Montefeltro: tecniche innovative per lo studio delle trasformazioni urbane. Cennamo, G.M., (ed.) Processi di analisi per strategie di valorizzazione dei paesaggi urbani. I luoghi storici tra conservazione e innovazione. Ermes. Servizi editoriali integrati S.r.l., Ariccia (RM) 2016, pp. 105-115. ISBN 978-88-6975094-6.

Baratin, L., Scicolone, G., Lonati, S., 2016b. Conservation Digital Report: standard documentation in Cultural Heritage, EUROGRAPHICS Workshop on Graphics and Cultural Heritage.

Baratin, L., Cattaneo, A., 2016c. SICaR restoration of religious works of art in Urbino. Pelosi, C., Agresti, G., Lanteri, L. (ed.) 8th european symposium on religious art, Restoration \& conservation. pp. 62-65. ISSN 2036-1122 ISBN 978-88-4044377-5.

Bertozzi, S., Baratin, L., Moretti, E. 2016. "The Fortification System of the City of Urbino: The Case Study of Valbona Gate from 3D Surveys to GIS Applications for Dynamic Maps." : $645-56$.

Baratin, L., Gasparetto, F., Lonati, S., Scicolone, G., 2017. Conservation Digital Report: a digital system for the documentation of Cultural Heritage in case of disaster. Gambardella, C. (ed.) WORLD HERITAGE and DISASTER. Knowledge, Culture and Representation. La scuola di Pitagora editrice, Napoli 2017, ISBN 978-88-6542-582-4.

Baratin, L., Bertozzi, S., Cattaneo, A., Devecchi, A., Gasparetto, F., 2017. Sperimentazione di un approccio partecipativo alla conservazione. Gli ambienti interni e gli 
arredi dei collegi universitari di Urbino. Le nuove frontiere del restauro. Trasferimenti, Contaminazioni, Ibridazioni, Scienza e Beni Culturali, Edizioni Arcadia ricerche, pp.143-153, ISSN 2039-9790, ISBN 978-88-95409-21-4.

Lo Turco, M., Mattone, M., Rinaudo, F. 2017. Metric survey and bim technologies to record decay conditions. The International Archives of the Photogrammetry, Remote Sensing and Spatial Information Sciences, Volume XLII-5/W1 GEOMATICS \& RESTORATION - Conservation of Cultural Heritage in the Digital Era.

Yaagoubi, Reda et al. 2019. "SEH-SDB : A Semantically Enriched Historical Spatial Database for Documentation and Preservation of Monumental Heritage Based on CityGML." : 53-68. 